\title{
Rapid Assessment Framework for Modeling Stakeholder Involvement in Infrastructure Development
}

\author{
Christine Prouty $^{a}{ }^{*}$, Eric S. Koenig $^{b}$, E. Christian Wells ${ }^{b}$, Rebecca K. Zarger ${ }^{b}$, Qiong Zhang $^{a}$ \\ ${ }^{a}$ Department of Civil and Environmental Engineering, University of South Florida, 4202 E. Fowler Ave., Tampa, \\ FL, 33620, USA \\ ${ }^{b}$ Department of Anthropology, University of South Florida, 4202 E. Fowler Ave., Tampa, FL, 33620, USA \\ * Corresponding author: Christine Prouty \\ Telephone number: +1-601-497-1472 \\ E-mail address: cprouty@mail.usf.edu
}

Other author: Eric S. Koenig

Other author: E. Christian Wells

Other author: Rebecca K. Zarger

Other author: Qiong Zhang
E-mail address: eskoenig@mail.usf.edu

E-mail address: ecwells@usf.edu

E-mail address: rzarger@usf.edu

E-mail address: qiongzhang@usf.edu

(C) 2016. This manuscript version is made available under the Elsevier user license http://www.elsevier.com/open-access/userlicense/1.0/ 


\begin{abstract}
There is increasing global interest in the adoption of sustainable wastewater systems due to the significant human and environmental health benefits of properly treating wastewater effluents prior to being discharged into surface waters and local communities. Research demonstrates that wastewater infrastructure is sustainable only when multiple stakeholder groups are involved. Here we draw on the principles of integrated environmental resources management and sociocultural analyses to develop a framework for rapidly assessing stakeholder involvement in a proposed centralized wastewater project in Placencia, Belize. We demonstrate this framework by analyzing survey responses to measure stakeholder involvement and discuss the model's utility to inform groupings based on similarity in engagement. We employ BrainerdRobinson similarity coefficients to rapidly assess stakeholders' involvement and produce a consensus score. We then evaluate the goodness of fit between these scores and correspondence analysis scatterplots. We conclude that Brainerd-Robinson scores provide a rapid means for determining relevant groupings of stakeholders, particularly in resource-scarce settings. Nuanced stakeholder groupings can inform researchers, policy makers, development workers, and community organizations about ways in which individuals are engaging with a project, providing a way to target suitable initiatives to promote sustained involvement.
\end{abstract}

Keywords: Stakeholder Involvement, Rapid Assessment Framework, Wastewater Infrastructure, Sustainability 


\section{Introduction}

Stakeholder involvement has been an important factor in the sustainable development literature for decades, especially concerning infrastructure projects (Gleick, 1998; Holmes, 2000; Holmes, 2002; Torres, 2003; Fam and Mitchell, 2013; Tjandraatmadja et al., 2013). Most recently, the United Nations (U.N.) has reflected the growing emphasis on stakeholder involvement by articulating it as a necessary feature within the Sustainable Development Goals (SDG). While each SDG asserts a broad expectation for the next decade of development (i.e., SDG 6 encourages the global community to make efforts to, "ensure access to water and sanitation for all'), the sub-tasks (targets) provide instructions on improving specific aspects of stakeholder involvement, particularly building the capacity of community members and strengthening partnerships across various sectors (UN, 2015). However, some researchers (Rahman, 1993; Pretty, 1994; Daniels and Walker, 1996, 2001; Dent et al., 2013) have critiqued the means by which stakeholders are engaged, suggesting that some efforts are superficial attempts at involving the community without sufficiently addressing the complexities of implementing projects within a local context (e.g., diverse opinions, attitudes, beliefs, politics).

Particularly for capital-intensive infrastructure projects such as a centralized wastewater treatment system, the individuals on the ground (i.e. engineers, contractors) have little to no formal social science training to assess the varying degrees of stakeholder involvement, consensus, or awareness of project goals. Some authors provide practitioners with strategies and processes to engage community members in local projects to promote sustainability (Pretty, 1994; Bass et al., 1995; FAO, 1998; Rietbergen-McCracken and Narayan, 1998; Schmeer, 1999; Hjortsoe et al., 2005; Salentine and Johnson, 2011), while others extend the participatory approach by also assessing and grouping stakeholders according to their level of involvement 
(Arnstein, 1969; Romney et al., 1986; Pretty, 1995; Garro, 2000; Beierle, 2002; Lienert, 2006;

Lynam et al., 2007; Paolisso, 2007; Prell, Hubacek, and Reed, 2009; Reed et al., 2009;

Gatewood, 2012; Olson, 2013; Starkl et al., 2013). Each of these approaches requires a significant amount of time and resources to be spent conducting fieldwork (i.e. executing surveys or facilitating focus groups). However, there are no studies that provide a rapid assessment framework that guides non-social scientists through a robust, context-adaptive means to gauge stakeholder involvement. Instead, ambiguity and subjectivity remain regarding an approach to identify stakeholders and the ways they are grouped based on their involvement with a project.

Accordingly, a review and synthesis of stakeholder analysis literature is used as the foundation for developing and demonstrating this rapid assessment framework. The framework consists of two parts - a suite of factors to use for questionnaire development and a methodology for rapidly assessing the results of the questionnaire. The suite of factors is synthesized from the literature review to elicit fundamental themes of stakeholder involvement that span various contexts. After the questionnaire is executed in the field, the resulting data is assessed to consider a community's knowledge and access to information about a proposed centralized wastewater project in Placencia, Belize. Brainerd-Robinson (BR) coefficients are calculated to quickly determine consensus among stakeholders as they are grouped in various ways. In support of the BR scores, results from correspondence analyses are plotted to visually represent conformity among the same groupings. Finally, the study highlights the advantages of using the BR approach as a method to quickly assess a complex variable in resource-scarce settings.

\section{Assessing Stakeholder Involvement}


Stakeholder involvement is a concept that is addressed in wastewater literature, particularly by outlining its benefits in relation to successful system management (Holmes, 2002). This section underscores three assessments of stakeholder engagement that have emerged from the literature review: stakeholder analysis, social network analysis, and cultural consensus analysis.

\section{Stakeholder Analysis}

Stakeholder analysis is an approach used for understanding stakeholder involvement by specifying the different types of stakeholders and their roles in a project (Prell, Hubacek, and Reed, 2009; Reed et al., 2009). In their review of stakeholder analysis methods in natural resource management, business, and development fields, Reed and others (2009) note three primary aims of stakeholder analysis, which include the following: 1) define social and natural phenomenon affected by a decision or project outcome; 2) identify individuals and groups who are affected by or can affect the phenomenon; and 3) prioritize individuals and groups for involvement in decision-making processes.

From these aims, one can use various methods to investigate the roles, strategies, and initiatives stakeholders use to productively navigate policies, promote consensus, and share information between groups (Wedel et al., 2005; Reed et al., 2009). Some ethnographic and social science methods are focus groups, semi-structured interviews, and surveys. The goal of these methods is to identify general stakeholder categories, contacts, and their attributes by employing top-down (analytical) and bottom-up (reconstructive) procedures (Reed et al., 2009).

\section{Social Network Analysis}

As the importance of interactions and associations among stakeholders became clear to researchers, three major methods were developed to investigate these relationships; actor-linkage 
matrices, knowledge mapping, and social network analysis (Reed et al., 2009). Actor-linkage matrices characterize the type of relationships between stakeholders in a two-dimensional table using key words, often describing the stakeholder relationships as cooperating, complementary, or conflicting (Reed et al., 2009). Knowledge mapping is used to analyse the flows and content of knowledge exchange across a stakeholder network to inform models of power distribution. Finally, social network analysis assigns coded numbers to ethnographic data from interviews, observations, and surveys to represent the presence and strength of relational ties to quantify and assess the structure of stakeholder networks for a particular domain (Prell, Hubacek, and Reed, 2009; Reed et al., 2009). Thus, the analysis facilitates anemic (insider)quantitative perspective rather than a top-down (external) assessment of relationships, relative levels of power, influence, and participation within a network of stakeholders (Prell, Hubacek, and Reed, 2009).

\section{Cultural Consensus Analysis}

As with other participatory methods used for analyzing stakeholder involvement, cultural consensus analysis mathematically models the relative levels of agreement within and between groups of informants with respect to their knowledge about a particular cultural domain or topic (Romney et al., 1986; Garro, 2000; Paolisso, 2007; Gatewood, 2012). The primary modeling tool is called Q-mode factor analysis and reflects the similarity among factors by calculating a normalized score based on the variance between groups. Originally, the "cultural consensus theory" was developed to estimate a groups' degree of consensus and "accuracy" in their responses to questions that sample a particular cultural domain. Each question type (e.g. true/false, multiple-choice) assumes a finite amount of responses and only one statically probable “correct" answer (Romney et al., 1986). The informants' responses then generate an "answer key" matrix based on the probability and level of confidence in the consensus to the questions 
(Romney et al., 1986). This matrix is used to compare each individual sampled to "objectively" characterize cultural knowledge among a group in comparison to the "answer key" (Romney et al., 1986). This approach accounts for response bias (the probability that an informant guesses an answer to a question based on the number of possible responses) to estimate individual "cultural competence" (the probability that the respondent knows the "consensus" answer to questions rather than guesses them) (Romney et al., 1986). An individual's "cultural competence" is calculated as a percentage using a weighted computation of aggregate responses representing a pattern of shared knowledge (Romney et al., 1986).

The cultural consensus analysis enables researchers to estimate the relative amount of cultural knowledge for a particular domain that is shared within a population and assesses how the knowledge is socially distributed (e.g., whether understandings follow a uniform, subcultural, specialist, random, or personal pattern) (Gatewood, 2012). Thus, the primary utility of the cultural consensus framework is its ability to compare the strength, congruence, and distribution of cultural beliefs and knowledge both within and between groups, and even in cross-cultural contexts, by drawing on analysis of coded responses to standardized questionnaires (Romney et al., 1986). This analysis has been applied across a wide variety of research contexts to understand intra-cultural variation in how individuals learn and distribute information for particular sociocultural domains including fisheries management (Paolisso, 2007), traditional ecological knowledge (Olson, 2013), and conceptions of health and illness (Romney et al. 1986; Garro, 2000), to name a few. However, the framework generally has not been applied in the context of development projects such as the case of this centralized wastewater system, likely because cultural consensus research requires ethnographic data collection and subsequent analysis. 


\section{Site Background: Placencia Peninsula, Belize}

To demonstrate our framework to model stakeholder involvement, we consider the Placencia Peninsula (Figure 1), a narrow 15 mile long isthmus located on the southeastern coast in the Stann Creek District of Belize. The peninsula extends as a spit of land south of the small community of Riversdale on the mainland, rising less than three meters above sea level (Ariola, 2003). It is acutely vulnerable to the effects of storm surge from tropical storms and hurricanes due to its low elevation (King et al., 1989, 1992; Walker, 1973; Boles et al., 2011). In the last 15 years, the peninsula has experienced a rapid expansion of tourism development including foreign-owned resorts and condominiums; much of this construction continues in periodic spurts. These developments have led to extensive clearing of coastal mangroves, dredging, and filling along the coastline resulting in coastal erosion, sedimentation, and nutrient discharge into the adjacent ecosystem (Boles et al., 2011).

Figure 1 Map of the Placencia Peninsula (prepared by Z. E. Darley)

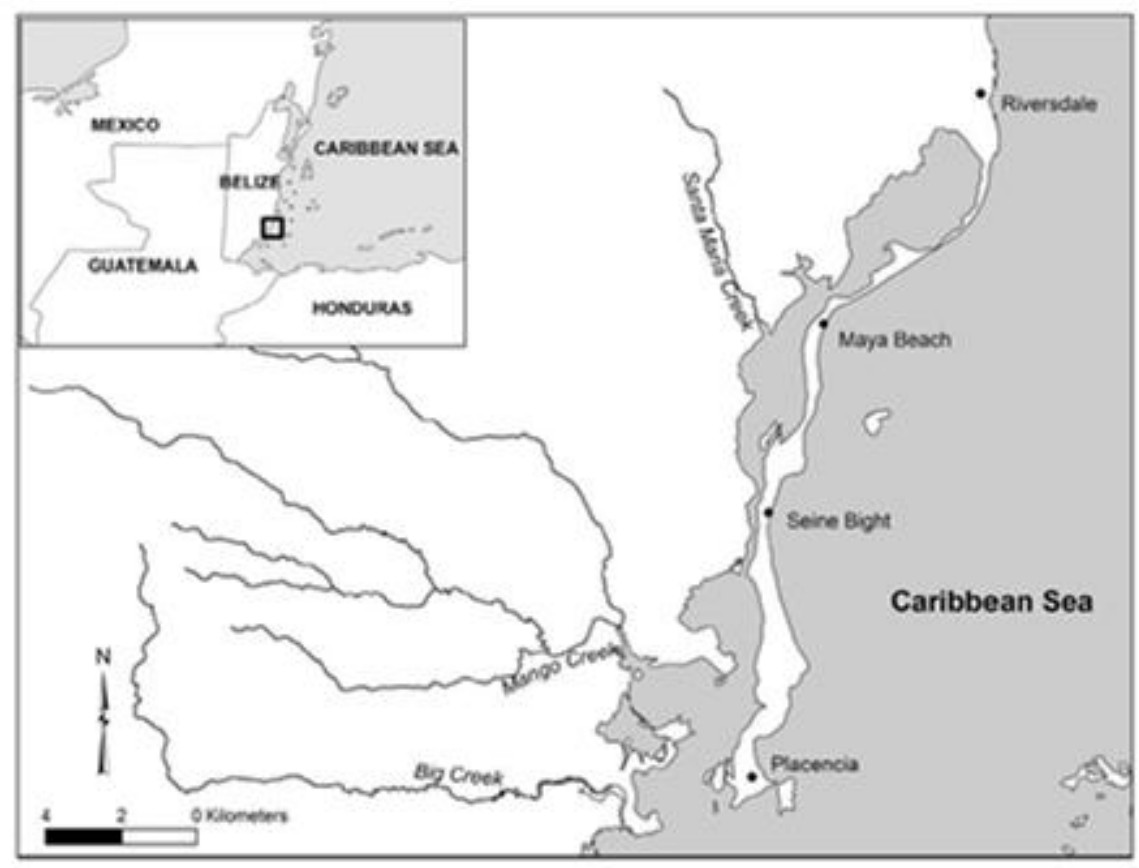


Placencia is a multi-ethnic, predominantly Creole village containing over 1,500 permanent residents located at the southern end of the narrow peninsula (Statistical Institute of Belize, 2011). North of Placencia village is an area of tourism, transportation, and residential development funded principally by foreign investment (Boles et al. 2011). Just north of this development is Seine Bight village, which also is a multi-ethnic, predominantly Garifuna indigenous community, whose residents have had tense relations with Placencia (Statistical Institute of Belize, 2011; Flores, 2013). The tensions are largely structured by political differences, racism, village border disputes, and uneven economic development between the villages (Boles et al., 2011; Spang, 2014). Four kilometers north of Seine Bight village is Maya Beach, a community of roughly 400 residents consisting of a primarily transient population of North American and European expatriates, a population that has grown from an initial Canadian real estate development in 1964 (Vernon and Young-Westby, 2014). Lastly Riversdale, a historically Creole fishing village of over 500 residents containing a large demographic of Mestizo residents, anchors the northern end of the peninsula to the mainland and extends into adjacent banana plantations (Spang, 2014).

\section{Research Context}

On the peninsula, the primary form of wastewater infrastructure is two-chambered concrete septic tanks (Halcrow, 2012; Wells et al., 2016). Previous studies and recent surveys confer that many of these decentralized systems undergo little or no routine maintenance (Halcrow, 2012). The resulting un- or minimally-treated wastewater is likely rich in nutrients that are being discharged into local ecosystems deteriorating the water quality (Halcrow, 2012; Wells et al., 2016). Concerns about wastewater disposal have also been raised in response to this rapid tourism development (Boles et al., 2011; Halcrow, 2012). Since residents and business on 
the peninsula primarily use septic systems, reports have arisen after storm surges of rashes and other health risks from wading through standing water mixed with minimally treated wastewater (Boles et al., 2011). Furthermore, the discharge of poor quality effluents from tourist resorts and residences on the peninsula has contributed to nutrient loading in coastal waterways (Boles et al., 2011; Roots and Reef, 2011).

In response to concerns about coastal water quality and public health, especially with punctuated flows of tourists between high and low seasons, and the unmitigated impacts of climate change and growth projections for the peninsula, the Government of Belize has proposed a BZ \$25 million integrated water and wastewater treatment system for the peninsula with support from the Inter-American Development Bank Caribbean Regional Fund for Wastewater Management to be managed by the private water and wastewater utility Belize Water Services Limited (BWSL) (GEF CReW, 2012; BWSL, 2013). This project's goal is to support economic development, particularly tourism, and improve the quality of life of the residents by way of environmental improvements associated with access to a centralized water and wastewater treatment system (GEF CReW, 2012). Although many residents and businesses recognize the need for a centralized wastewater system with expanding tourism development, some have expressed concerns about the infrastructural specifications and socio-economic and environmental impacts of the proposed system, especially regarding the costs of the installation and servicing, transparency to stakeholders, and loss of community revenue sources (Wells et al., 2016). By leveraging the data and resources from community collaborations, this research presents a framework that considers the form and relative degree to which stakeholders are aware of and engage with the proposed project. 


\section{Methods}

Survey Development and Administration

The literature review guided the development of a context-specific field questionnaire that aimed to elicit information about factors that directly and indirectly influence a stakeholders' participation with a project. While an in-depth explanation of the development of the questionnaire is out of the scope of this study, Table 1 presents a list of factors that impact a stakeholder's involvement.

-Table 1: Direct and indirect factors to be considered during the development of a questionnaire to determine stakeholder involvement

Direct Factors

Role/function within a stakeholder group

Type and level of participation in a project

Institutional relationships between stakeholder groups

Relative level of power to guide decisionmaking and resource allocation in a project

Extent of knowledge and information dissemination about a project

\section{Indirect Factors}

Interest in using the proposed project

Interest in participating in the implementation of the project

Demand or need for the system

Current or future access to and use of the system

Perceived benefits of having access to or using the system

Perceived risks of engaging with the project

To investigate the direct factor of knowledge transfer and access to information about the centralized wastewater project, our research draws on a stratified sample of 155 digital responses to the questionnaire using the KoBo application, an open-source tool for smartphones (Anokwa, 2011; Cairns, 2014; http://www.kobotoolbox.org). KoBo is an effective and versatile survey data collection tool for many areas where a rapid assessment study is needed since the application is free and can be used to program, collect, upload, sync, and analyse data with only internet access and a smartphone (Anokwa, 2011). The Kobo Toolbox online platform allows researchers to 
easily design and upload questionnaires to the smartphones using a user-friendly interface along with free technical support. We used this application to design a 10-30 minute digital survey targeting residents, workers residing off the peninsula, and tourists over 18 to gauge their perceptions about themes relating to water, waste, energy, the environment, and tourism management on the peninsula. Between three summer field seasons (2013-2015), individuals representing diverse ethnic identities and stakeholder sectors were recruited to participate.

Our focus in analyzing the responses to the questionnaire is to use the data to meaningfully distinguish the ways stakeholders were engaging with a project. Table 2 presents the four questions from the full-length survey, introduces possible answers, and outlines their goals. The analysis employs two methods that produce normalized values of similarity between categorical responses or demographic groups - the Brainerd-Robinson (BR) approach produces a score that numerically reflects similarities whereas the correspondence analysis produces a figure showing a spatial representation of a group's consensus. The goals of both are similar, but the argument will be made that the BR methodology is the more suitable fit for this rapid assessment framework and the correspondence analysis should be supplemental to the BR values.

\section{Brainerd-Robinson Approach}

The Brainerd-Robinson approach normalizes the responses to categorical and scalar variables to produce a matrix of similarity scores that can be used to compare groups (Brainerd, 1951; Robinson, 1951; Cowgill, 1990; Lipo et al., 2015). This score (BR) is determined by summing the absolute value of differences among two groups when comparing them based upon the same type of characteristic, artifact, or response as seen in Equation 1. The summation or similarity score is based upon a 200-point scale and then normalized to that of a 0-1-point scale. 
Table 2: An excerpt of the questionnaire portion of the Stakeholder Involvement Framework that reflect stakeholders' degree of knowledge and access to information about the wastewater system proposed for the peninsula
Type of Question
Question
Possible Answers
Goal of Question

\begin{tabular}{|c|c|c|c|}
\hline $\begin{array}{l}\text { Free response } \\
\text { categorical question }\end{array}$ & $\begin{array}{l}\text { What types of information, if any, } \\
\text { have you been provided (by } \\
\text { BWSL) about the new water and } \\
\text { wastewater management system? } \\
\text { For instance, pamphlets, } \\
\text { community meetings? }\end{array}$ & $\begin{array}{l}\text { Individuals freely respond; } \\
\text { researchers write-in responses }\end{array}$ & $\begin{array}{l}\text { To gauge the respondents' } \\
\text { awareness of the proposed } \\
\text { integrated system; To differentiate } \\
\text { those who have heard of the project } \\
\text { by the types of information they } \\
\text { have received }\end{array}$ \\
\hline $\begin{array}{l}\text { Single-select categorical } \\
\text { question }\end{array}$ & $\begin{array}{l}\text { How important is the treatment of } \\
\text { wastewater is to you? }\end{array}$ & $\begin{array}{l}\text { (1) Unimportant (2) Neutral (3) } \\
\text { Important }\end{array}$ & $\begin{array}{l}\text { To assess respondents' perceived } \\
\text { need for wastewater treatment on } \\
\text { the peninsula }\end{array}$ \\
\hline
\end{tabular}


The normalization is determined by subtracted the similarity score that was calculated from 200 , which is considered a perfectly similar score or $100 \%$ similarity among any two groups.

$$
B R=200-\sum_{i=1}^{N}\left|P_{i A}-P_{i B}\right|
$$

The strength of using the BR analysis in this study is that the methodology is useful in resource-scarce scenarios such as a field setting because it only requires a researcher to access a calculator and sufficient data without the need for a computer and statistical software. Correspondence Analysis

Correspondence analysis is a non-parametric method that provides a spatial representation of data that aims to ease and expedite the comparison of similarity between categorical groups of different variables (Greenacre, 2007; Bernard and Gravlee, 2014). The analysis method compares proximal relationships between two or more categorical variables, although it does not provide a measure of statistical significance because it does not assume a (normal) distributional pattern. Since it requires only categorical variables, the analysis allows for the input of ordinal variables, nominal variables, and discrete intervals through ratio variables (such as quartiles), although generating distinct categories from a continuous variable is generally not encouraged for correspondence analysis applications (Starkweather and Herrington 2014).

Correspondence analysis often is performed by using statistical software packages such as IBM SPSS statistics ${ }^{\circledR}$ to translate the information from coded field responses into a two-way cross-tabulation table of frequencies and then into a scatter plot graphic. Cross-tabulation frequencies in the table are computed into a multi-dimensional scale that is then used to generate points on the scatter plot (Hill, 1974). These points can be used to visually assess relationships between categories as they relate to particular dimensional axes. According to Lee (1996), “... 
the goal is to have a global view of the data that is useful for interpretation." However, Lee (1996) warns that this visible interpretation of similarities between groups should be handled with caution, particularly when the relationships are not considered statistically significant.

\section{Results}

To demonstrate the utility of this framework and its ability to elicit meaningful information for grouping stakeholders, we consider four examples assessing various demographic variables, including: respondent's age, place of residence, occupation, and monthly income. We first apply the Brainerd-Robinson (BR) dimension reduction method to assess the degree of consensus among respondents to the stakeholder involvement questionnaire, and highlight its functionality in a time- and resource-scarce setting because the associated score can be calculated with a pen and paper, using basic mathematical equations, and no computer software. In support of the BR scores, we present correspondence analysis results to reflect the same demographic categories and variables about stakeholders' knowledge as a visual representation of respondents' degree of conformity. Finally, we discuss the implications of assigning respondents into contextually appropriate stakeholder groups based on the degree of conformity.

\section{Grouping by Respondents' Place of Residence}

Consider the BR scores in Table 3 that reflect the consensus regarding respondents' perceived risk of wastewater to human health among groups with differing places of residence. The matrix of BR similarity values is calculated by applying Equation 1. The consensus or similarity scores are calculated based on 200-point scale and then normalized to that of a 0-1point scale. The results from Table 3 range from $0.79-0.96$ as pairwise comparisons are made 
between non-identical groups. On the other hand, when a location is compared to itself, the rightful consensus score, as seen in the diagonal of the matrix, is 1 - full consensus or perfectly similarity. Depending upon the purpose of the study, thresholds for BR scores are put in place to limit comparisons between groups that are above or below a specific similarity coefficient. The highest, non-identical comparison is between locations away from the peninsula and villages nearby the peninsula with a $0.96 \mathrm{BR}$ score. The values calculated for neighboring villages, Placencia and Seine Bight, have a moderately high similarity score of 0.85. Similarly, Seine Bight respondents and those located away from the peninsula also have a moderately high similarity score of 0.92 . Lastly, the lowest BR value for the groupings of respondents' place of residence and their perceptions of the risk associated with wastewater is between Placencia residents and those from locations away from the peninsula- 0.79 .

Table 3 Brainerd Robinson Values Showing Consensus Between Places of Residence on Perceptions of the Risk Associated with Wastewater

\begin{tabular}{|c|c|c|c|c|}
\hline & Placencia & Seine Bight & $\begin{array}{l}\text { Villages nearby } \\
\text { the peninsula }\end{array}$ & $\begin{array}{l}\text { Locations } \\
\text { away from the } \\
\text { peninsula }\end{array}$ \\
\hline Placencia & 1.00 & & & \\
\hline Seine Bight & 0.85 & 1.00 & & \\
\hline $\begin{array}{l}\text { Villages nearby the } \\
\text { peninsula }\end{array}$ & 0.82 & 0.96 & 1.00 & \\
\hline $\begin{array}{l}\text { Locations away } \\
\text { from the peninsula }\end{array}$ & 0.79 & 0.92 & 0.96 & 1.00 \\
\hline
\end{tabular}

Next, the same information is cross-tabulated and input into a correspondence analysis to produce a figure of stakeholders' consensus regarding knowledge and access to information about the proposed wastewater system (Starkweather and Herrington, 2014). The categorical questions were inserted as variables containing three (column) and four (row) possible response 
categories. The null hypothesis is that respondents grouped by residence would not influence their perception of the risk associated with wastewater.

Using IBM SPSS statistical software, a correspondence cross-tabulation table, row and column profiles, and confidence statistics were then computed to generate two dimensions for plotting the association between variables in Figure 2. Inertia represents the variance for each dimension and total variance attributable to the model. Chi-Squared $\left(\chi^{2}\right)$ is the probability that the dimensions created are significantly related to the input variables. For Figure 2, the individual variance $($ inertia $=\mathrm{i})$ is listed next to the dimensions $(\mathrm{i}=0.029$ for Dimensions 1 and $\mathrm{i}$ $=0.001$ for Dimension 2). The total variance between the computed dimensions accounted for by the model $(3.0 \%)$ is the sum of the individual variances. Lastly, the cross-tabulation tables indicate that there is not a significant relationship between the computed dimensions for these variables $\left(\chi^{2}=3.278, p=0.773\right)$.

Figure 2 depicts the correspondence analysis plot that shows all stakeholders grouped by residence are in consensus about wastewater either being of medium or severe health risk. This result is consistent with the BR scores that are all greater than 0.785 , thus reflecting a large degree of consensus. Further comparing the correspondence plot to the BR scores, we can see relative similarities. For example, villages nearby the peninsula and those located away from the peninsula had the largest BR value, revealing their consensus regarding respondents' perceptions of risk; in the Figure 2, these two points are closest to one another in comparison to their proximity to other respondents' locations. While relative comparisons can be made between the BR scores and correspondence plots, due to the statistical insignificance, we cannot use the correspondence model to definitively explain trends between these categories. 
Figure 2 Correspondence analysis plot comparing respondents' place of residence with their perceptions for wastewater's risk to human health among KoBo survey respondents between the 2013 and 2015 field seasons. Total inertia $\mathrm{i}=0.03$, Chi-Squared $\chi^{2}=3.278$, Significance $\mathrm{p}=$ 0.773 .

\section{Correspondence Analysis of Respondents' Place of Residence and Perceptions of the Risk Associated Wastewater to Human Health}

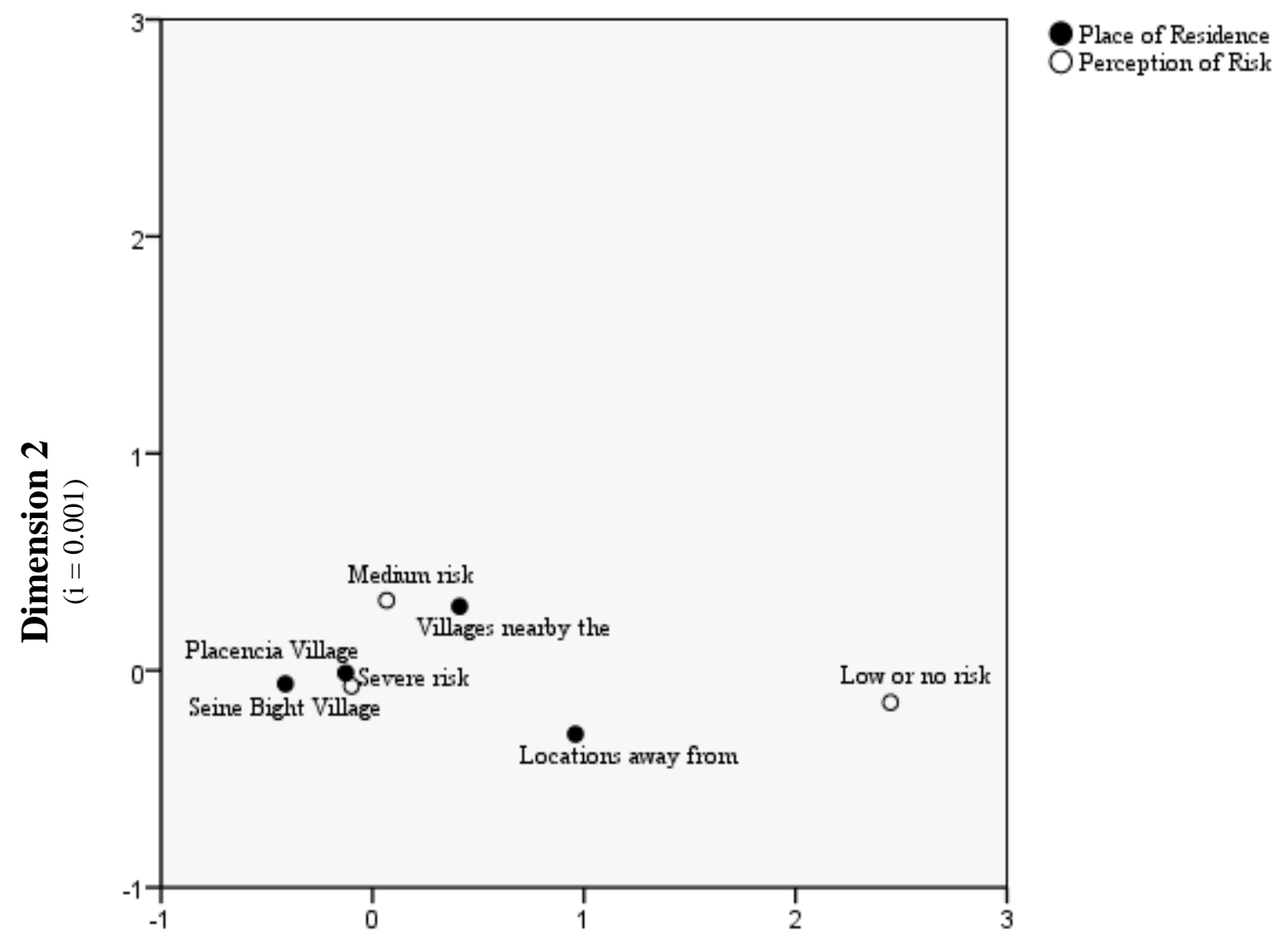

\section{Dimension 1}

$(\mathrm{i}=0.029)$

Grouping by Respondents' Age Range

Furthermore, consider Table 4 that uses age range as the control variable and lists BR scores between groups revealing their conformity about the type of information with which they engage about the proposed wastewater project in Placencia. In Table 4, all values are calculated as 0.97 and higher. The pair-wise comparison between age ranges 18-25 and 41-65+ yields the lowest BR score, albeit relatively high overall. On the other hand, the highest value recorded for non-identical groups is 0.99 for 18-25 and 26-40 year-olds and 26-40 and 41-65+ year-olds. 
Table 4 Brainerd Robinson Values Showing Consensus Among Age Ranges About the Type of Information with which they Engage Regarding the Centralized Wastewater System in Placencia

\begin{tabular}{l|ccc}
\multicolumn{1}{c}{$\mathbf{1 8 - 2 5}$} & $\mathbf{2 6 - 4 0}$ & $\mathbf{4 1 - 6 5 +}$ \\
\hline $\mathbf{1 8 - 2 5}$ & 1.00 & & \\
$\mathbf{2 6 - 4 0}$ & 0.99 & 1.00 & \\
$\mathbf{4 1 - 6 5 +}$ & 0.97 & 0.99 & 1.00
\end{tabular}

The correspondence analysis for the same case used the categorical variable for respondents' age range (18-25, 26-40, and 41-65+ years) as the row field while the variable for forms of media ('flyer,' 'BWS provided information,' 'TV or newspaper,' 'community meetings,' 'word of mouth,' 'survey,' or 'no information provided' inclusively) was input into the column field. The null hypothesis is that residents grouped by differing age brackets would not influence the form of media they received about the proposed centralized wastewater system. Figure 3 shows that $31 \%$ of the total variance between the computed dimensions is accounted for by the model with $20.6 \%$ and $10.3 \%$ coming from dimensions 1 and 2 respectively. Next, regarding the Chi-Squared values, there is not a significant relationship between the computed dimensions for these variables given $\chi^{2}=11.15$ and $p=0.516$. Again, the null hypothesis cannot be rejected and we cannot have confidence that this correspondence model explains the trends regarding the different types of media accessed by residents of varying age groups. However, Figure 3 does show us that information provided directly by BWSL or displayed on the TV or in the newspaper were the least popular types of information accessed across all age groupings about the proposed project. 
Figure 3 Correspondence analysis plot comparing Placencia resident age ranges with the types of information they accessed for knowledge about the proposed BWS centralized wastewater treatment system among KoBo survey respondents between the 2014 and 2015 field seasons. Total inertia $\mathrm{i}=0.31$, Chi-Squared $\chi^{2}=11.15$, Significance $\mathrm{p}=0.516$.

\section{Correspondence Analysis of Respondents' Age Range and Type of Information Accessed for Knowledge about the Proposed Centralized Wastewater System}

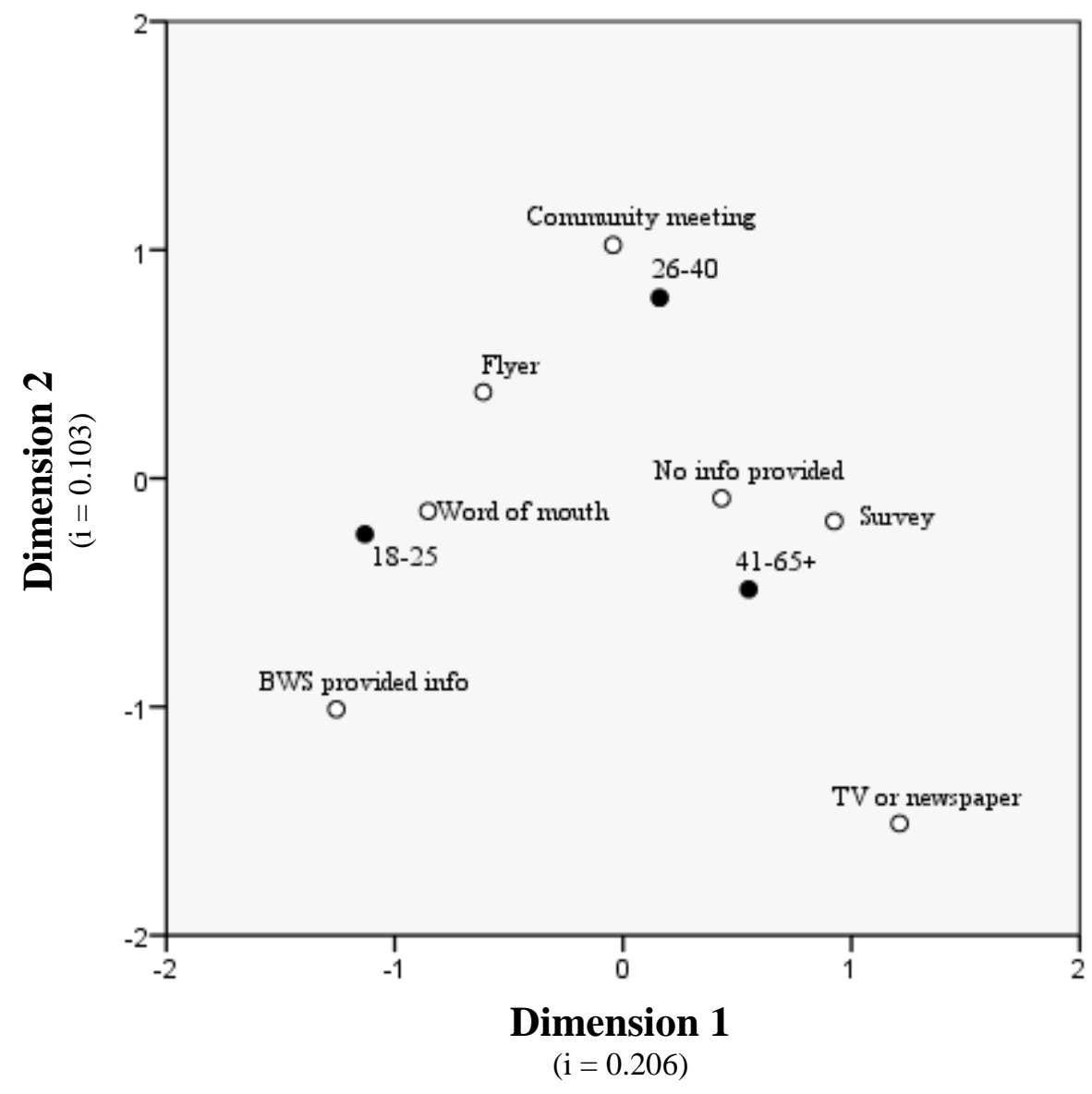

Age Range

Type of Information

Moreover, despite more than 39\% of residents surveyed during the 2014-2015 field

seasons reported that they had received no information about the proposed BWS project. In spite of this, there was similarity among those age groups that did receive or engage with some form of media about the proposed system, namely flyers for the 18-25 and 26-40 year-olds.

Additionally, community meetings seem to be the characteristic means for 26-40 year-olds to access information, while surveys and word of mouth were typical for 41-65+ and 18-25 yearolds respectively. Differences in the types of information that respondents reported engaging 
with could be due to variations in the ways they described the forms of media (e.g., surveys vs. flyers). Although these similarities are not significant, Figure 3 visually reflects a quick representation of the stratification of the data.

\section{Grouping by Respondents' Occupation}

For this group of BR scores, Table 5 shows the consensus among stakeholders with various occupations and their preferred decision-maker for Placencia's wastewater system. All of the BR scores for each pair-wise comparison reflect values greater than 0.9 , with the consensus between government or civil servants and the restaurant industry as the lowest -0.93 . The high similarity scores between respondents grouped by occupation reflect few relative differences between their perceptions of their preferred decision-makers for wastewater system provision. However, cross-tabulation of residents' perceptions by occupation indicate there are differences, but the BR scores do not reflect that well. Thus, correspondence analysis applied to this case illustrates the minor differences in respondent perceptions about who should make decisions about the wastewater project on the peninsula, but overall shows various stakeholder industries in general consensus about decision-making authority. 
Table 5 Brainerd Robinson values showing consensus among residents grouped by stakeholder sector/occupation concerning who they think should make decisions about Placencia's wastewater

\begin{tabular}{|c|c|c|c|c|c|c|c|c|c|}
\hline & $\begin{array}{c}\text { Homemaking } \\
\text { or retired }\end{array}$ & Tourism & $\begin{array}{l}\text { Construction } \\
\text { and } \\
\text { development }\end{array}$ & Education & $\begin{array}{c}\text { Hotels / } \\
\text { real estate } \\
\end{array}$ & Fishing & $\begin{array}{c}\text { Government or } \\
\text { civil service }\end{array}$ & Sales & Restaurants \\
\hline $\begin{array}{l}\text { Homemaking or } \\
\text { retired }\end{array}$ & 1.00 & & & & & & & & \\
\hline Tourism & 0.98 & 1.00 & & & & & & & \\
\hline $\begin{array}{l}\text { Construction } \\
\text { and development }\end{array}$ & 0.99 & 0.99 & 1.00 & & & & & & \\
\hline Education & 0.98 & 1.00 & 1.00 & 1.00 & & & & & \\
\hline $\begin{array}{l}\text { Hotels or real } \\
\text { estate }\end{array}$ & 0.99 & 0.99 & 1.00 & 0.99 & 1.00 & & & & \\
\hline Fishing & 1.00 & 0.97 & 0.98 & 0.98 & 0.99 & 1.00 & & & \\
\hline $\begin{array}{l}\text { Government or } \\
\text { civil service }\end{array}$ & 0.99 & 0.97 & 0.98 & 0.97 & 0.98 & 1.00 & 1.00 & & \\
\hline Sales & 0.94 & 0.97 & 0.96 & 0.96 & 0.95 & 0.94 & 0.93 & 1.00 & \\
\hline Restaurants & 0.93 & 0.96 & 0.95 & 0.96 & 0.95 & 0.93 & 0.93 & 1.00 & 1.00 \\
\hline
\end{tabular}


In the correspondence analysis, the categorical variable for the respondent's occupational industry included options for homemaking or retired, tourism, construction and development, education, hotels or real estate, fishing, government or civil service, sales, and restaurants. Those responses were entered into the row field while the variable for resident perceptions of who should make decisions about wastewater treatment systems (including options for 'the community,' the 'tourism industry,' 'individual community members,' 'BWS,' 'Village council,' 'Specialists,' and a 'team of local, nation, and business leaders') was input into the column field. The null hypothesis is that residents grouped by their stakeholder industry sector would not influence who they think should hold power over wastewater decision-making.

Figure 4 shows that there is a substantial amount of variation between stakeholder industry groupings and perceptions of who should make decisions about wastewater treatment. Approximately $43 \%$ of the total variance between the computed dimensions is accounted for by the model, and there is no significant relationship between the computed dimensions for these variables $\left(\chi^{2}=43.145, p=0.672\right)$. One explanation for the variation in responses grouped by occupation is because many residents hold multiple jobs on the peninsula which makes answering a question about one's stakeholder industry fairly difficult, thus complicating the way residents are assigned into one occupational group or another. As such, at least in the case of the Placencia Peninsula, categorizing stakeholders by their occupation(s) and the industries in which they work may not be useful when attempting to discern stakeholder consensus with respect to a particular topic. In response to this concern, future iterations of the questionnaire, should ask for the respondent's most current occupation or the occupation in which they have spent the most time. Furthermore, it is also likely that the high variability, albeit not directly reflected by the BR scores is due to the large number of options for respondents' opinions about who should be the 
decision-makers for wastewater systems on the peninsula. Consequently, a broader spectrum of response options dilutes the likelihood for consensus among groups. In order to discern this consensus, a smaller, finite value of possible responses should be used in the questionnaire. The minimal amount and most appropriate response options can be verified by field testing the surveys multiple times prior to formal data collection, reviewing similar, site-specific surveys that may have been used in the past, and asking community partners for feedback.

Figure 4 Correspondence analysis of KoBo survey responses during the 2013-2015 field seasons comparing stakeholders' occupational sectors and who they think should have decision-making powers about wastewater treatment systems on the peninsula. Total inertia $\mathrm{i}=0.436$ (for multiple dimensions), Chi-Squared $\chi^{2}=43.145$, Significance $\mathrm{p}=0.672$.

\section{Correspondence Analysis of Respondents' Occupation and Response about Who Should Make Decisions about Wastewater on the Peninsula}

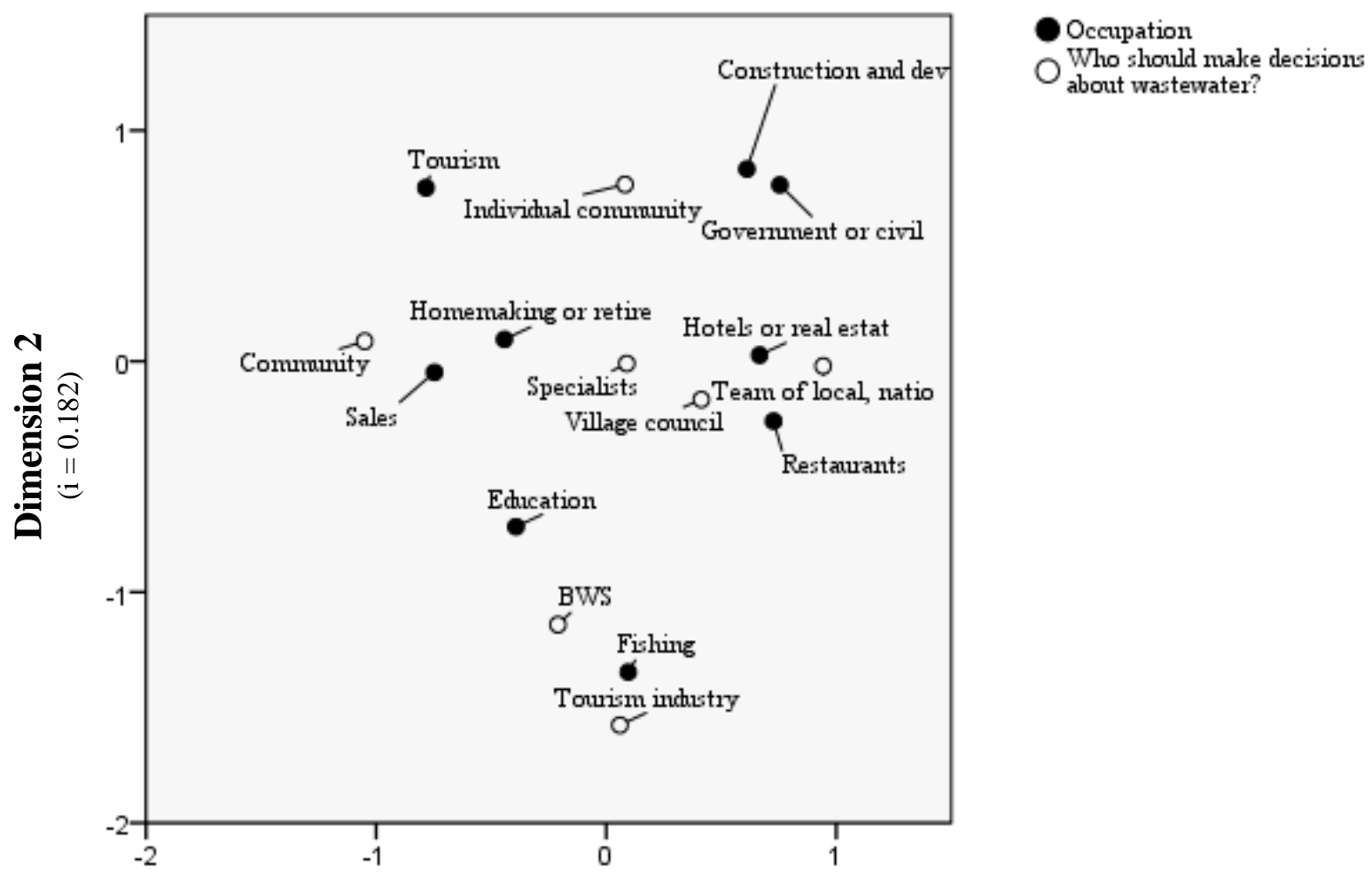

\section{Dimension 1}

$$
(i=0.122)
$$


Grouping by Respondents' Income

Lastly is the consideration of the similarities between respondents of various income brackets regarding their perception about the importance of treating wastewater. Table 6 depicts a small matrix of BR scores ranging from 0.82 to 0.96 . The highest $\mathrm{BR}$ score is associated with residents who earn between $\$ 0-\$ 1,500$ and $\$ 1,501-\$ 3,000 \mathrm{BZD} /$ month, whereas the lowest is between those in the two upper income brackets (i.e. $\$ 1,501-\$ 3,000$ and $\$ 3,001+\mathrm{BZD} /$ month).

Table 6 Brainerd Robinson values showing consensus in the perceived importance of wastewater treatment based on groupings of income level

\begin{tabular}{|c|c|c|c|}
\hline & $\begin{array}{l}0-1,500 \\
\text { BZD/month }\end{array}$ & $\begin{array}{l}\text { 1,501 - 3,000 } \\
\text { BZD/month }\end{array}$ & $\begin{array}{l}\text { 3,001+ } \\
\text { BZD/month }\end{array}$ \\
\hline 0-1,500 BZD/month & 1.00 & & \\
\hline 1,501-3,000 BZD/month & 0.96 & 1.00 & \\
\hline $3,001+$ BZD/month & 0.86 & 0.82 & 1.00 \\
\hline
\end{tabular}

However, Figure 5 displays the scatter plot from the correspondence analysis that provides additional information to interpret the similarities among income groups. For this analysis, the categorical variable for residents' monthly income includes $\$ 0-1,500, \$ 1,501-3,000$, and $\$ 3,000+$ Belize dollars (BZD)/month. This information was entered into the row field while the variable for resident perceptions of the importance of treating wastewater ('Not important,' 'Neutral,' and 'Important') was input into the column field. The null hypothesis was that residents grouped by their level of monthly income would not influence the perceived importance of treating wastewater. Overall, $5.2 \%$ of the total variance between the computed dimensions is accounted for by the model and there is not a significant relationship between the computed dimensions for these variables $\left(\chi^{2}=4.107, \mathrm{p}=0.392\right)$. Consequently, this means that we can neither reject the null hypothesis nor have confidence that this correspondence model can 
explain the trends that exist between residents with varying levels of income regarding their perceived importance in treating wastewater. Visually, however, Figure 5 shows a high degree of consensus between residents within the two lower income brackets that treating wastewater is important to them. On the other hand, the correspondence analysis scatter plot also shows the highest income bracket $(\$ 3,001+\mathrm{BZD} /$ month) as gravitating towards a 'Neutral' response regarding their perceptions of the importance of treating wastewater.

Figure 5 Correspondence analysis of KoBo survey responses during the 2014 and 2015 field seasons comparing respondents' income groups with their perceptions of the importance of treating wastewater on the peninsula. Total inertia $\mathrm{i}=0.052$, Chi-Squared $\chi^{2}=4.107$, Significance $\mathrm{p}=0.392$.

Correspondence Analysis of Respondents' Income and Their Perception of the Importance of Treating Wastewater

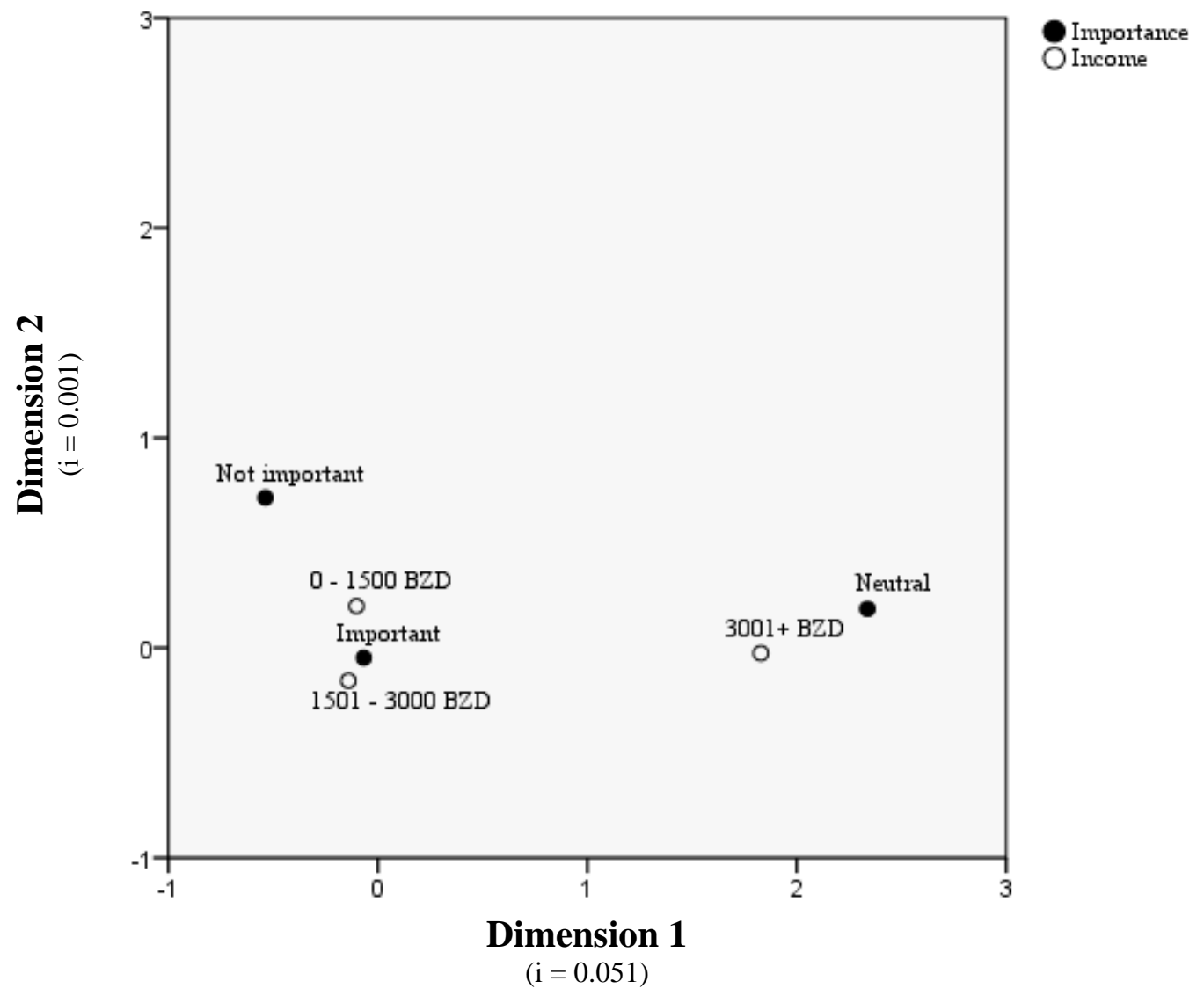




\section{Conclusions}

This study investigates the utility of a rapid assessment framework that quantifies stakeholder involvement. The framework attempts to balance the tension between the amount of time and resources it takes to collect and analyse meaningful field data about stakeholders. In this study, the framework used a range of responses to the questionnaire from Placencia, Belize. These responses were considered using two different approaches - the Brainerd-Robinson method and correspondence analysis. These examples illustrate how two non-parametric data analysis methods might be applied to generate similarity scores and group field-based survey responses; the correspondence analysis also visually supports the BR scores with scatter plots showing consensus.

While the BR approach provides insight into stakeholder involvement, the framework has limited utility to produce generalizations about stakeholders. There are nuances that abound in any grouping, and full consensus or homogeneity is unlikely. For instance, the rapid assessment framework does little in considering the historical, inter-personal, socio-economic, or sociopolitical complexities of stakeholders. Secondly, prior to conducting fieldwork, it is important to test the site-specific questionnaire to ensure all possible response options will be populated so that each method functions properly. This could be addressed by field-testing the questionnaire, seeking feedback from colleagues, and by calculating a statistically significant number of people to sample (e.g. relative to the community, school, county, or organization's size) prior to executing the questionnaire. Next, it is important to consider the potential bias in participant selection whether this is due to the convenience sampling or limited access to some stakeholders (e.g. language barriers, education, trust). Lastly is the importance of constructing the questionnaire in a way that elicits as many answers as possible in categorical or single-select 
free-response formats. Without such prior considerations time and resource savings associated with use of this framework may not be realized because excessive amounts of time could be spent coding string responses from during data processing or skewed and/or insufficient data could pose a problem during data analysis.

The BR results showed instructive ways that responses should (income or place of residence) and should not (occupation) be grouped. However, the BR approach does have limitations because it is unlikely to be the best data analysis method for comparing a small group or binary classification (e.g. gender) where responses are expected to have a great degree of similarity. This is true because BR similarity scores are calculated by determining a relative difference between pair-wise groups. As such, if there are only a few groups and a high degree of similarity, the method does not mathematically reflect intricate differences in the scores. Instead, the BR approach finds its niche as the preferred methodology in this study because it is a quick way to reveal relative consensus (or difference) while also reducing dimensional complexity among groupings.

This BR approach can rapidly categorize different groups based on demographic variables to determine whether the control variable is useful for distinguishing groups of stakeholders for a particular case study. For example, grouping questionnaire respondents by their occupation when asking about their perceptions of who should have power in the decisionmaking processes about wastewater systems has limited utility for discerning stakeholder groups in our study. In this scenario, too many response categories were listed on the questionnaire, so the similarity scores were all very high. Rather than reflecting consensus, this categorization of stakeholders demonstrated a dilution of respondent opinions, yielding the suggestion that future questionnaires must have fewer response categories. Finally, the BR method addresses some of 
the logistical shortcomings of cultural consensus analysis in interdisciplinary studies of stakeholder involvement because it gleans aspects of community-based cultural perspectives, but does so in an expedited way using a site-specific questionnaire tailored to a particular infrastructure project. As such, time and resources spent on fieldwork are justifiably reduced. Overall, this study provides a valuable framework for researchers and development workers to rapidly assess stakeholders based upon their responses to geographically and community-specific questionnaires with the purpose of grouping them into contextually appropriate stakeholder categories. Discernment of stakeholder categories in this way can facilitate targeted improvements for engagement in infrastructure and resource management projects, ultimately to support project adoption and long-term viability. 


\section{Acknowledgments}

This material is based in part upon work supported by the National Science Foundation under Grant Number 1243510. 


\section{Works Cited}

Anokwa Y. 2011. Experiences with KoBo and ODK in Bolivia. Open Data Kit: Magnifying Human Resources through Technology, 2011. http://opendatakit.org/2011/07/experiences-withkobo-and-odk-in-bolivia/ [6 May 2015]

Ariola E. 2003. Characterization of a tropical estuarine system: The Placencia Lagoon. http://www.coastalzonebelize.org/wpcontent/uploads/2010/04/Characteristics\%20of\%20P\%20Lagoon\%20.pdf [6 September 2015] Arnstein SR. 1969. A ladder of citizen participation." Journal of the American Institute of planners 35.4: 216-224.

Bass S, Dalal-Clayton DB, Pretty JN. 1995. Participation in strategies for sustainable development. London, UK: Environmental Planning Group, International Institute for Environment and Development.

Beierle TC. 2002. The quality of stakeholder-based decisions. Risk analysis 22.4: 739-749.

Belize Water Services Limited (BWSL). 2013. Ongoing Projects: Integrated Water and Sanitation Program for the Placencia Peninsula (IWSPPP) 2013. http://www.bws.bz/ouroperations/projects-initiatives/ongoing-projects/ [20 February 2015]

Bernard HR, Gravlee CC. 2014. Handbook of methods in cultural anthropology. Lanham: Maryland. Rowman \& Littlefield.

Boles E, Anderson A, Cawich R, Figueroa V, Franco J, Grijalva D, Mai D, Mendez K, Peralta A, Requena L, Rodriguez M, Sanchez E. 2011. Rapid Assessment of Effects and Issues Related to Development in the Placencia Area, Dry Season 2011.

http://www.saveourpeninsula.org/placencia-assessment.pdf [19 July 2015]

Brainerd GW. 1951. The place of chronological ordering in archaeological analysis. American antiquity 16.4: 301-313.

Cairns MR. 2014. Environment, Rights, and Waste in Bolivia: Addressing Water and Sanitation Processes for Improved Infrastructure. Dissertation: University of South Florida, Tampa.

Cowgill GL. 1990. Why Pearson's $r$ is not a good similarity coefficient for comparing collections. American Antiquity 1990: 512-521.

Daniels SE, Walker GB. 1996. Collaborative learning: improving public deliberation in ecosystem-based management. Environmental impact assessment review 16.2: 71-102.

Daniels SE, Walker GB. 2001. Working through environmental conflict: The collaborative learning approach. http://digitalcommons.usu.edu/sswa_facpubs/60/ [5 May 2015] 
Dent D, Dubois O, Dalal-Clayton B. 2013. Rural planning in developing countries: supporting natural resource management and sustainable livelihoods. London, UK: Earthscan Publications, Ltd..

Fam DM, Mitchell CA. 2013. Sustainable innovation in wastewater management: lessons for nutrient recovery and reuse. Local Environment 18.7: 769-780.

Flores Sr. GP. 2013. A Brief History of Seine Bight Village. In Way Bak Den: Preserving \& Celebrating Creole and Garifuna Culture on the Placencia Peninsula, Belize. Lisa Carne (ed). Inter-American Development Bank, Cultural Development Program.

Food and Agriculture Organization of the United Nations (FAO). 1997. Improving agricultural extension: A reference manual. Robert P. Bentz, Andrew J. Sofranko, and Burton E. Swanson (eds).

Garro LC. 2000. Remembering what one knows and the construction of the past: A comparison of cultural consensus theory and cultural schema theory. Ethos 28.3: 275-319.

Gatewood JB. 2012. Cultural models, consensus analysis, and the social organization of knowledge. Topics in cognitive science 4.3: 362-371.

GEF CReW. 2012. Establishing wastewater management systems in the Placencia Peninsula: Belize's first generation project under CReW. CReW's Lines 1.2: 3-9.

Gleick PH. 1998. Water in crisis: paths to sustainable water use. Ecological applications 8.3: 571-579.

Greenacre M. 2007. Correspondence analysis in practice. Barcelona: Spain. CRC press.

Halcrow. 2012. Feasibility Study for the Placencia Peninsula Pilot Wastewater Management System: Final Report. Submitted to the Ministry of Finance, Government of Belize. Halcrow, a CH2M Hill Company, Tampa, FL.

Hill MO. 1974. Correspondence analysis: a neglected multivariate method. Applied statistics 1974: 340-354.

Hjorts $\varnothing$ CN, Christensen SM, Tarp P. 2005. Rapid stakeholder and conflict assessment for natural resource management using cognitive mapping: The case of Damdoi Forest Enterprise, Vietnam. Agriculture and Human Values 22.2: 149-167.

Holmes PR. 2000. Effective organizations for water management. International Journal of Water Resources Development 16.1: 57-71. 
Holmes PR. 2002. Building Stakeholder Support for Success. Water and Wastewater International. http://www.waterworld.com/articles/wwi/print/volume-17/issue6/features/building-stakeholder-support-for-success.html [12 November 2014]

King RB, Baillie IC, Dunsmore JR, Gray DA, Pratt JH et al. 1992. Land resource assessment of Northern Belize Natural Resources Institute Bulletin 43:1-513.

King RB, Baillie IC, Dunsmore JR, Grimble RJ, Johnson MS, Williams JB, Wright ACS. 1989. Land resource assessment of Stann Creek District, Belize. Kent, UK: Overseas Development Natural Resources Institute.

Lee BL. 1996. Correspondence Analysis." LL Thurstone Psychometric Laboratory Research Memorandum. http://sunsite.csd.univie.ac.at/ViSta/vista-frames/pdf/chap11.pdf [11 June 2016]

Lienert J, Thiemann K, Kaufmann-Hayoz R, Larsen TA. 2006. Young users accept NoMix toilets-a questionnaire survey on urine source separating toilets in a college in Switzerland. Water science and technology 54.11-12: 403-412.

Lipo CP, Madsen ME, Dunnell RC. 2015 A Theoretically-Sufficient and ComputationallyPractical Technique for Deterministic Frequency Seriation. PloS one 10.4: 1-31, doi:10.1371.

Lynam T, de Jong W, Shiel D, Kusumanto T, Evans K. 2007. A review of tools for incorporating community knowledge, preferences, and values into decision making in natural resources management. Ecology and society 12.1: 5-20.

Olson EA. 2013 Anthropology and traditional ecological knowledge: a summary of quantitative approaches to traditional knowledge, market participation, and conservation. Culture, Agriculture, Food and Environment 35.2: 140-151.

Paolisso M. 2007. Cultural models and cultural consensus of Chesapeake Bay blue crab and oyster fisheries. NAPA Bulletin 28.1: 123-135.

Prell C, Hubacek K, Reed MS. 2009. Stakeholder analysis and social network analysis in natural resource management. Society and Natural Resources 22.6: 501-518.

Pretty JN. 1994. Alternative systems of inquiry for a sustainable agriculture. IDS bulletin 25.2: 37-49.

Pretty JN. 1995. Participatory learning for sustainable agriculture. World development 23.8: 1247-1263.

Rahman MA. 1993. People's self-development. London: Zed Books. 
Reed MS, Graves A, Dandy N, Posthumus H, Hubacek K, Morris J, Prell C, Quinn CH, Stringer LC. 2009. Who's in and why? A typology of stakeholder analysis methods for natural resource management. Journal of environmental management 90.5: 1933-1949.

Rietbergen-McCracken J, Narayan-Parker D. 1998 Participation and social assessment: tools and techniques. World Bank Publications.

Robinson WS. 1951. A method for chronologically ordering archaeological deposits. American antiquity 16.4: 293-301.

Romney AK, Weller SC, Batchelder WH. 1986. Culture as consensus: A theory of culture and informant accuracy. American anthropologist 88.2: 313-338.

Roots and Reef. 2011. Coastal Water Quality Problems. Roots and Reef, 10.15: 7.

Salentine S, Johnston A. 2011. Tools for Data Demand and Use in the Health Sector:

Stakeholder Engagement Tool. http://www.cpc.unc.edu/measure/resources/publications/ms-1146-e/at_download/document [6 February 2016]

Schmeer K. 1999. Guidelines for conducting a stakeholder analysis. PHR, Abt Associates.

Spang LH. 2014. A real Belizean: Food, identity and tourism in Belize. Dissertation Indiana University.

Starkl M, Brunner N, Lopez E, Martinez-Ruiz JL. 2013. A planning-oriented sustainability assessment framework for peri-urban water management in developing countries. Water Research 47.20: 7175-7183.

Starkweather, Herrington. 2014. Correspondence Analysis. In SPSS Short Course, 2014. Denton, Texas: University of North Texas Research and Statistical Support. http://www.unt.edu/rss/class/Jon/SPSS_SC/Module9/M9_Correspondence/SPSS_M9_Correspon dence1.htm [30 March 2016]

Statistical Institute of Belize (SIB). 2010. Main Results of 2010 Population and Housing Census. http://www.statisticsbelize.org.bz/dms20uc/dynamicdata/docs/20110505004542_2.pdf [9 January 2014]

Tjandraatmadja G, Sharma AK, Grant T, Pamminger F. 2013. A decision support methodology for integrated urban water management in remote settlements. Water Resources Management 27.2: 433-449.

Torres A. 2003. Public acceptance is not optional. Water Environment and Technology 15.12: 60-61. 
United Nations General Assembly (UN). 2015. Transforming our world: the 2030 Agenda for Sustainable Development. New York: United Nations.

Vernon L, Young-Westby Sr. H. 2014. Footprints on the Beach to Paradise: Placencia and Its Environs. Belize City, Belize: Henry Young Enterprises.

Walker SH. 1973. Summary of climatic records for Belize. Land Resources Division, Overseas Development Administration. http://www.worldcat.org/title/summary-of-climatic-records-forbelize/oclc/701790334 [19 July 2015]

Wedel JR, Shore C, Feldman G, Lanthrop S. 2005 Toward an anthropology of public policy. The ANNALS of the American Academy of Political and Social Science 600.1 (2005): 30-51.

Wells EC, Zarger RK, Whiteford LM, Mihelcic JR, Koenig ES, Cairns MR. 2016. The Impacts of Tourism Development on Perceptions and Practices of Sustainable Wastewater Management on the Placencia Peninsula, Belize. Journal of Cleaner Production 111:430-441.

DOI:10.1016/j.jclepro.2014.08.050. 